\title{
Genome Survey Sequencing of Nomocharis forrestii, Assembly of Its Complete Chloroplast Genome and Analysis of Simple Sequence Repeat (SSR) Markers
}

Da Zhang

School of Agriculture, Yunnan University

LianLian Li

School of Agriculture, Yunnan University

XueWei Wu ( $\nabla$ wuxuewei@ynu.edu.cn )

School of Agriculture, Yunnan University

TianXi Wang

School of Agriculture, Yunnan University

Na Ping

School of Agriculture, Yunnan University

HaiYing Liu

School of Agriculture, Yunnan University

YongPing Li

School of Agriculture, Yunnan University

YiPing Zhang

Flower Research Institute, Yunnan Academy of Agricultural Sciences

LiHua Wang

Flower Research Institute, Yunnan Academy of Agricultural Sciences

\section{Research Article}

Keywords: Nomocharis forrestii, SSR marker, chloroplast genome, genome survey

Posted Date: December 15th, 2020

DOl: https://doi.org/10.21203/rs.3.rs-124261/v1

License: (c) (1) This work is licensed under a Creative Commons Attribution 4.0 International License.

Read Full License 
1 Genome Survey Sequencing of Nomocharis forrestii, Assembly of Its Complete

2 Chloroplast Genome and Analysis of Simple Sequence Repeat (SSR) Markers

3 Da Zhang ${ }^{a^{*}}$, LianLian $\mathrm{Li}^{{ }^{*}}{ }^{*}$, XueWei Wu ${ }^{a^{* *}}$, TianXi Wang a, Na Ping a, HaiYing Liu a,

$4 \quad$ YongPing $\mathbf{L i}^{\mathrm{a}}{ }^{\text {, YiPing }}$ Zhang ${ }^{\mathrm{b}}, \mathbf{L i H u a}$ Wang ${ }^{\mathrm{b}^{* *}}$

5 a School of Agriculture, Yunnan University, Chenggong District, Kunming, Yunnan 650091, China

6 blower Research Institute, Yunnan Agriculture Academy of Science, Panlong District, 650025,

7 Yunnan, China;

$8 \quad{ }^{*}$ Both authors contributed equally in preparing the manuscript.

9 ** Corresponding author: wuxuewei@ynu.edu.cn (X.W.Wu); 687514549@qq.com (L.H. Wang)

Abstract

Background: Nomocharis is a genus that is closely related to Lilium in the Liliaceae family. It's useful to study the influence of the uplift of the Qinghai-Tibet Plateau on plants and their biological diversity. Nomocharis is a genus of such plants, and research on this genus will be especially informative, considering the genetic diversity of flowers. However, the genetic information of Nomocharis has not been fully elucidated.

Results: To obtain a complete Nomocharis reference genome, the paper first performed a general survey. Next-generation sequencing (NGS) was utilized to perform de novo sequencing of the entire Nomocharis forrestii genome. In this study, the sequencing process yielded approximately 137.4 $\mathrm{Gb}$ of high-quality data, the total sequencing depth was approximately $63 \mathrm{X}$, and the Q30

21 ratio was $91.95 \%$; the estimated genome size was approximately $2.17 \mathrm{~Gb}$; the repetitive sequence content was approximately $84.7 \%$, the heterozygosity rate was $3.99 \%$, and the estimated GC content of the genome was $43 \%$. Furthermore, an annotated circular chloroplast gene map was generated, and a preliminary evolutionary analysis was performed. In addition, a total of 78,045 
high-quality SSR markers were developed.

Conclusion: Nomocharis forrestii has a $2.17 \mathrm{~Gb}$ heterozygous genome, its SSR markers are predominantly dinucleotides, and its chloroplast genome shows that Nomocharis forrestii and Lilium bakerianum have the highest homology followed by Lilium distichum. To the best of our knowledge, this report describes the first de novo whole-genome sequencing and assembly process to be performed for Nomocharis. The results of this study may provide new resources for the future genetic analysis and molecular breeding of Nomocharis.

Keywords: Nomocharis forrestii; SSR marker; chloroplast genome; genome survey

\section{Background}

Nomocharis is a genus closely related to Lilium in the Liliaceae family ${ }^{[1]}$. There are 7 species in this genus and 6 species in China. Among these species, Nomocharis pardanthina and Nomocharis meleagrina are endemic to China ${ }^{[2]}$. Nomocharis is distributed on the southeastern margin of the Qinghai-Tibet Plateau, being concentrated in northwestern Yunnan and adjacent areas, and only Nomocharis synaptica appears in northeastern India. Since Franchet established Nomocharis ${ }^{[3]}$ with Nomocharis pardanthina as the model species in 1889 , whether the genus was established as an independent genus and the scope of the genus have been controversial. For an extended period, scholars have had different opinions, resulting in frequent changes in the ownership of certain species within this genus and Lilium ${ }^{[1]}$. Nomocharis aperta and Nomocharis saluenensis in Nomocharis and Lilium lophophorum, Lilium souliei, and Lilium henrici in the genus Lilium have been moved back and forth between the two genera. Previously, scholars believed that Nomocharis was a young taxonomy newly derived from Lilium during the uplift of the 
Qinghai-Tibet Plateau ${ }^{[1,4]}$. Regardless of morphological characteristics ${ }^{[3,5,6]}$, geographic distribution ${ }^{[7]}$ or molecular properties ${ }^{[8,9,10]}$, both Nomocharis and Lilium are inextricably linked.

Therefore, research investigating the Nomocharis genome and chloroplast levels and analyzing the relationship between the two genera is of great significance not only for elucidating the phylogeny and evolution of Nomocharis and Lilium but also for studying the effects of the uplift of the Qinghai-Tibet Plateau on plants and on overall biological diversity.

A number of molecular biology research methods, such as the use of molecular markers, require large quantities of information regarding genomes and specific functional genes. To date, there are no research reports describing the whole genome of Nomocharis, and the lack of a reference genome has placed considerable restrictions on the research investigating Nomocharis molecular biology and genomics. Therefore, an investigation of the Nomocharis genome is essential $^{[11-16]}$.

Recently, next-generation sequencing (NGS) has developed rapidly. This technique provides scientists with faster and less expensive sequencing. Among many NGS sequencing platforms, Illumina is the most commonly used for molecular marker development ${ }^{[11-18]}$. This platform is preferred not only because it can use RCA products ${ }^{[19]}$ but also because it can use a bioinformatic platform for de novo assembly without reference to the genome sequence ${ }^{[20]}$. SSR markers are the most widely utilized molecular marker system. SSR markers for many species have been developed through NGS. The increase in the density of molecular markers can further promote molecular breeding and genome-wide association. Therefore, to study and provide resources for the Nomocharis genome for future research, research on the $N$. forrestii genome was performed using NGS technology. In addition, the whole genome sequence of $N$. forrestii will be employed 
for the development of SSR markers after assembly.

The chloroplast is a very important plant organelle with its own genome, and it produces energy through photosynthesis. Because chloroplasts have a highly conserved structure, the chloroplast genome has not only been employed as an useful research model, especially in phylogeny ${ }^{[21]}$, but it has also been utilized as a DNA barcode ${ }^{[22]}$ and for species protection and genome evolution ${ }^{[23]}$. To the best of our knowledge, there is no prior report on the Nomocharis chloroplast genome sequence, and the complete $N$. forrestii chloroplast genome is presented in this article.

\section{Result}

\section{Genome Sequencing and Sequence Assembly}

To sequence $N$. forrestii, we extracted DNA from fresh leaves. Through Illumina sequencing, the original sequencing data were approximately $137.4 \mathrm{~Gb}$, the total sequencing depth was approximately $63 \mathrm{X}$, and the Q30 ratio was $92.07 \%$. After sequencing quality control, total clean data were obtained, and the sample Q30 base percentage was not less than $90 \%$ with an approximately $63 \mathrm{X}$ depth of sequencing. From the 300-bp library obtained by sequencing, the first 10,000 reads were extracted and compared with the NT library. No abnormal comparisons, such as microorganisms and humans, were observed in the comparison results, and there was no contamination in the samples. The chloroplast data of the Lilium bakerianum chloroplast complete genome (NC_035592.1) with a genome size of 151,655 bp were utilized to evaluate the plastid content. Comparing the obtained high-quality data with the plastid sequence, the comparison indicated that the content of plastids was low, which did not affect the sequencing and assembly of 


\begin{tabular}{lllll}
\hline Raw/Clean & Read Number & Base Number(bp) & GC Content $(\%)$ & Q30(\%) \\
\hline Raw & $458,075,259$ & $138,014,716,200$ & 43.48 & 91.95 \\
Clean & $458,066,599$ & $137,419,979,700$ & 43.49 & 91.95 \\
\hline
\end{tabular}
assembly results are shown in Table 2 .

Table 1. Statistics of Nomocharis forrestii sequencing data
97

98

\begin{tabular}{lllll}
\hline & \multicolumn{3}{c}{ Scaffold } & \multicolumn{2}{c}{ Contig } \\
\cline { 2 - 5 } & Size(bp) & Number & Size(bp) & Number \\
\hline N50 & 233 & $1,623,797$ & 231 & $1,757,298$ \\
N60 & 233 & $1,623,797$ & 231 & $1,757,298$ \\
N70 & 167 & $2,179,339$ & 164 & $2,326,551$ \\
N80 & 151 & $2,936,082$ & 151 & $3,090,524$ \\
N90 & 134 & $3,726,880$ & 134 & $3,885,675$ \\
Longest & 112 & $4,675,373$ & 112 & $4,838,894$ \\
Total & 245,202 & 1 & 25,481 & 1 \\
\hline
\end{tabular}

98

Table 2. Information on the assembled genome sequences of Nomocharis forrestii 


\section{Genome Size Estimation and Genome Survey}

Using $137.4 \mathrm{~Gb}$ data for 17 -mer analysis, the total number of K-mers was determined to be $1.3 \times$ $10^{11}$, and the expected K-mer depth was observed to be 75 . According to the formula (genome size $=$ total number of K-mers/expected depth of K-mer), the genome size was calculated to be approximately $1.73 \mathrm{~Gb}$, and the genome size was estimated to be $2.17 \mathrm{~Gb}$ by GenomeScope software(Fig. 1). According to our experience, for complex genomes, the results of K-mer calculations may be smaller because the homologous K-mer is overlooked; therefore, the results predicted by GenomeScope were considered to be more accurate. The genome size of $N$. forrestii was estimated to be $2.17 \mathrm{~Gb}$.

len:2,171,937,001 bp uniq:15.3\% het:3.99\% kcov:14.9 err:0.752\% dup:0.985\% k:17

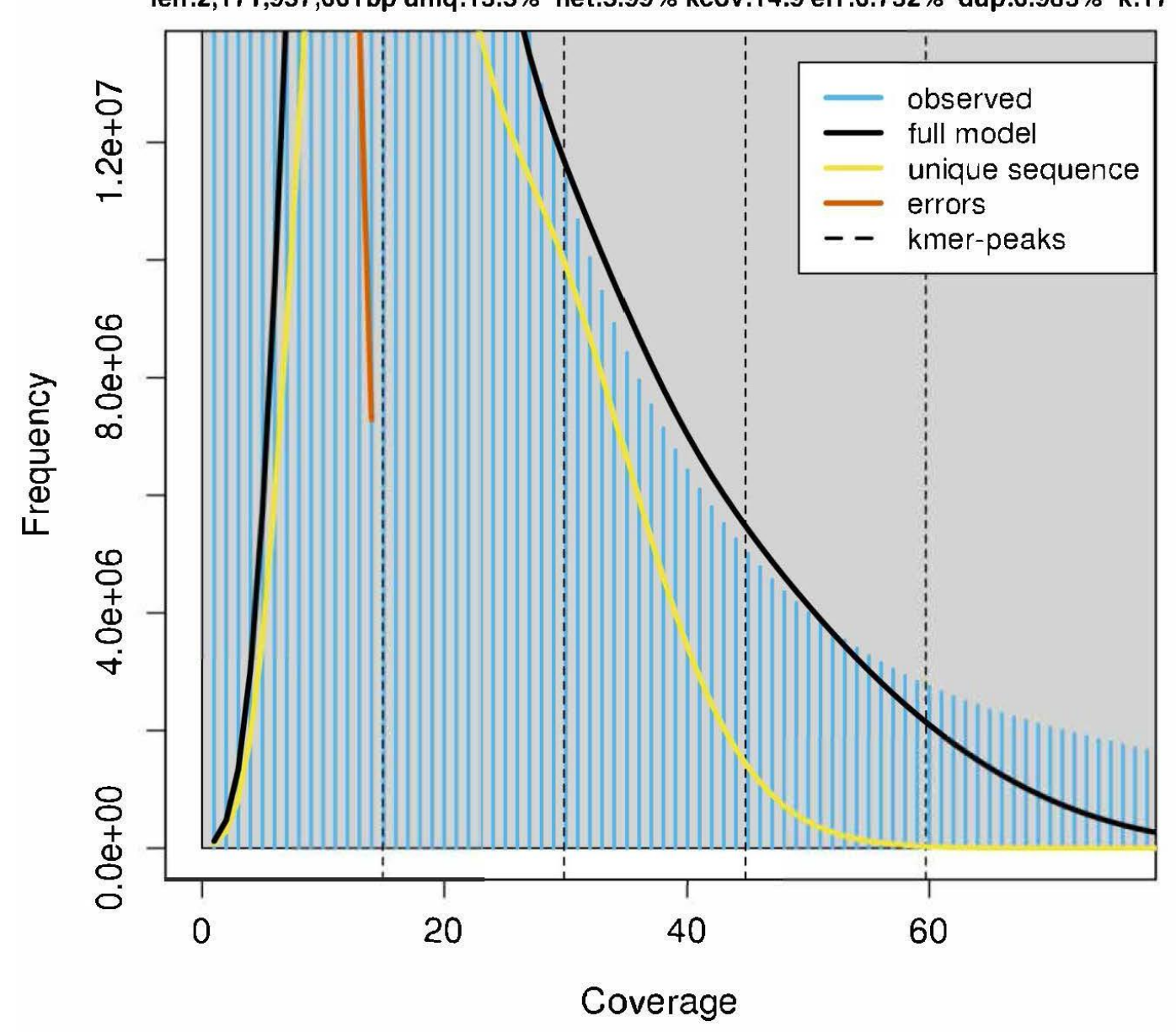

Fig. 1 K-mer distribution calculated by GenomeScope. The blue bar represents the observed K-mer 
distribution; the black line represents no K-mer; the red line represents the error model distribution; and the yellow line represents the maximum K-mer coverage specified in the model.

\section{Assembly of Chloroplast Genome}

The fully annotated annotation results indicate that the sample chloroplast genome is a circular double strand. Similar to most higher plant chloroplast genomes, there are two inverted repeats (IRs), namely, IRAs and IRBs; between the inverted repeats, there is a large single-copy region (LSC) and a small single-copy region (SSC) (Fig. 2). 

including 82 protein-coding genes (PCGs), 30 transfer RNA (tRNA) and 4 ribosomal RNA (rRNA) genes, of which 7 genes have more than 2 copies. The total GC content of the chloroplast genome was determined to be approximately $37.0 \%$. All chloroplast genes and classifications are shown in Table 3.

The chloroplast genome plays an important role in the reconstruction of plant phylogeny and evolutionary history. In our research, we utilized whole-genome sequences from 25 kinds of chloroplasts (15 of which are Liliaceae) and constructed a phylogenetic tree using MEGAX software $^{[24,25]}$. Using the neighbor-joining method ${ }^{[26]}, 1000$ bootstrap test repeats draw a proportional evolutionary tree; taking the number of base substitutions at each site as the unit, the maximum likelihood method ${ }^{[27]}$ is used to calculate the evolutionary distance (deleting all ambiguous positions of a single sequence pair). The branch length of the evolutionary tree is used to show the evolutionary distance of the phylogenetic tree, and the percentage of the replication tree of the bootstrap test is marked next to the branch. The use of the complete chloroplast genome relationships of Liliaceae plants. In this study, it was observed that Nomocharis forrestii and 


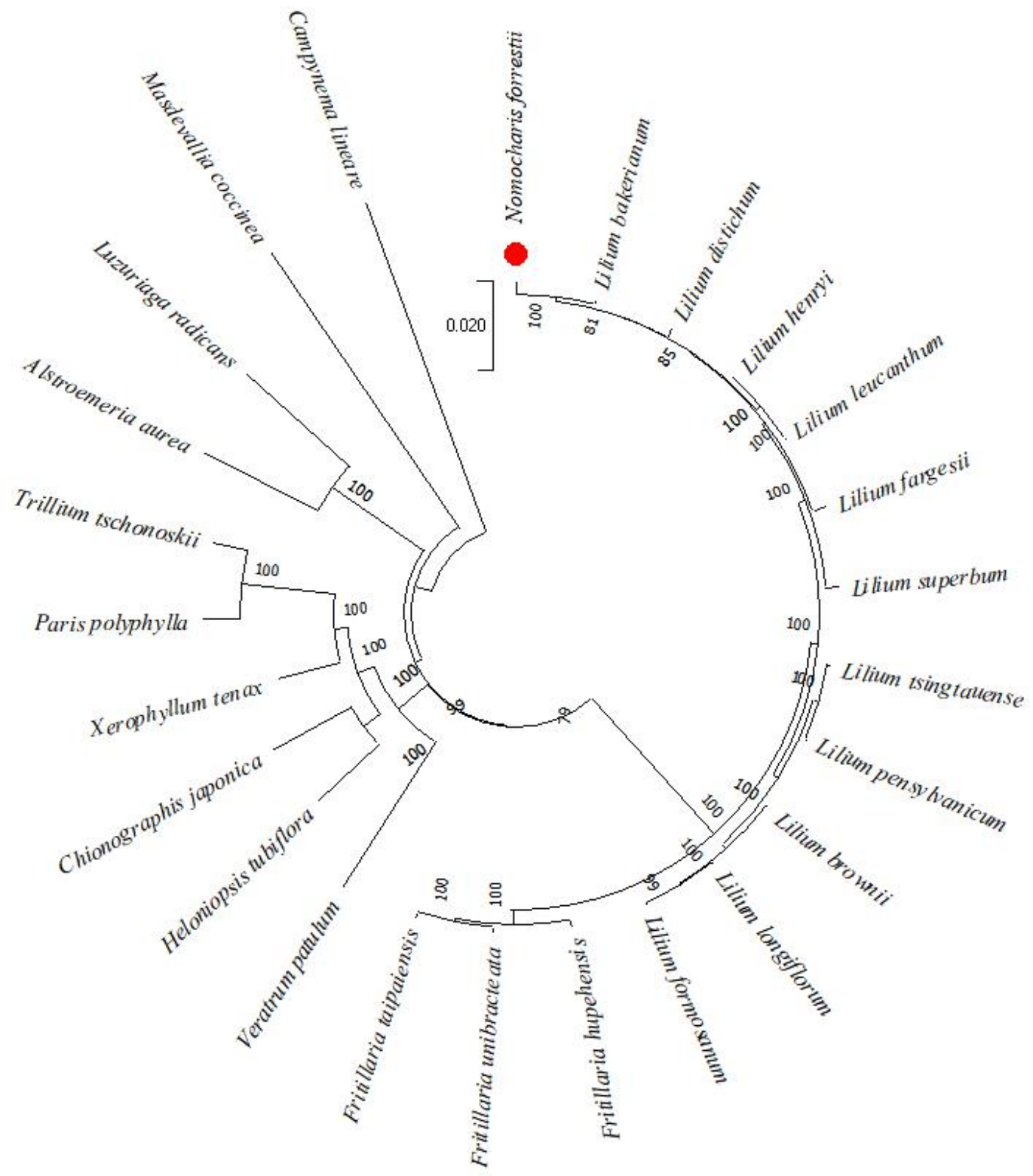




\begin{tabular}{|c|c|c|}
\hline \multirow[t]{10}{*}{ Functions } & Family name & Name of Gene(s) \\
\hline & Subunits of ATP & atp $A$, atpB, atpE, atpF, atpH, atpI \\
\hline & \multicolumn{2}{|l|}{ synthase } \\
\hline & \multicolumn{2}{|l|}{ Subunits of } \\
\hline & & $n d h A, n d h B, n d h C, n d h D, n d h E, n d h F, n d h G, n d h H$, \\
\hline & \multicolumn{2}{|l|}{ NADH } \\
\hline & & $n d h I, n d h J, n d h K$ \\
\hline & \multicolumn{2}{|l|}{ dehydrogenase } \\
\hline & Subunits & petA, petB, petD, pet $G$, petL, pet $N$ \\
\hline & \multicolumn{2}{|l|}{ cytochrome } \\
\hline Genes for & Subunits & \\
\hline photosynthesi & photosystem & $p s a A, p s a B, p s a C, p s a I, p s a J$ \\
\hline \multirow[t]{11}{*}{$\mathrm{s}$} & \multicolumn{2}{|l|}{ I } \\
\hline & Subunits & $p s b A, p s b B, p s b C, p s b D, p s b E, p s b F, p s b H, p s b I$, \\
\hline & photosystem II & $p s b J, p s b K, p s b L, p s b M, p s b N, p s b T, p s b Z$ \\
\hline & \multirow[t]{2}{*}{ Subunit of } & \\
\hline & & $r b c L$ \\
\hline & \multicolumn{2}{|l|}{ rubisco } \\
\hline & \multicolumn{2}{|l|}{ Subunit of } \\
\hline & \multicolumn{2}{|l|}{ Acetyl-CoA-carb } \\
\hline & \multicolumn{2}{|l|}{ oxylase } \\
\hline & \multicolumn{2}{|l|}{ c-type } \\
\hline & & $\operatorname{ccs} A$ \\
\hline Other genes & \multicolumn{2}{|l|}{ cytochrome } \\
\hline & synthesis gene & \\
\hline
\end{tabular}


Envelop

cemA

membrane

protein

Protease $\quad c l p P$

Maturase $\quad \operatorname{matK}$

Large subunit of $\quad r p l 14, r p l 16, r p l 2, r p l 20, r p l 22, r p l 23, r p l 32, r p l 33$,

ribosome $\quad r p l 36$

DNA dependent

rроA, rров, гроC1, гроC2

RNA

polymerase

Small subunit of

rps11, rps12, rps14, rps15, rps16, rps18, rps19,

ribosome

rps $2, r p s 3, r p s 4, r p s 7, r p s 8$

rRNA Genes

rrn16S, rrn23S, rrn4. $5 S, r r n 5 S$

$\operatorname{trnI}-G A U, \quad \operatorname{trn} A-U G C, \quad \operatorname{trnR}-A C G, \quad \operatorname{trnN}-G U U$,

$\operatorname{trn} L-U A G, \quad \operatorname{trnN}-G U U, \quad \operatorname{trn} V-G A C, \quad \operatorname{trn} L-C A A$,

trnY-GUA,trnT-UGU,trnN-GUU,trnT-GGU,trnL-CA

A,trnA-UGC,trnR-UCU,trnW-CCA, trn G-GCC,trnC-

tRNA Genes

GCA,trnE-UUC,trnP-UGG,trnQ-UUG,trnS-GGA,tr

Self-replicati

nI-CAU,trnS-GCU,trnL-UAA,trnS-UGA,trnV-UAC,t

on

rnK-UUU,trnF-GAA,trnL-UAG,trnD-GUC,trnM-CA

U,trnI-GAU,trnV-GAC,trnH-GUG,trnG-UCC,trnR-A

$C G$ 


$\begin{array}{llll}\text { Genes } & \text { of } & \text { Conserved open } \\ \text { unknown } & \text { reading } & \\ & \\ \text { function } & \text { frames }\end{array}$

\section{Genomic SSR Marker Development}

192 We employed the MISA software to search the assembled scaffold for SSR marks. A total of

19378,045 SSRs were identified from 2,847,542 scaffolds (Table 4). Regarding the base length of

194 SSR repetitive sequences (not including single nucleotides), dinucleotides accounted for $89.7 \%$,

195 trinucleotides accounted for $8.97 \%$, tetranucleotides accounted for $1.39 \%$, pentanucleotides

196 accounted for $0.17 \%$, and hexanucleotides accounted for $0.30 \%$ (Fig. $4 \mathrm{a}$ ).

Table 4. SSR types detected in the Nomocharis forrestii sequences

\begin{tabular}{ccc}
\hline Item & Number & Percentage $(\%)$ \\
\hline Total number of sequences examined & $5,772,746$ & - \\
Total size of examined sequences $(b p)$ & $1,155,548,885$ & 100.00 \\
Total number of identified SSRs & 63,472 & 84.33 \\
Number of SSR containing sequences & 53,523 & \\
Number of sequences containing more & & 9.39 \\
than 1 SSR & 5,957 &
\end{tabular}

Number of SSRs present in compound

formation

Mononucleotide

Dinucleotide 
Trinucleotide

Tetranucleotide

Pentanucleotide

Hexanucleotide
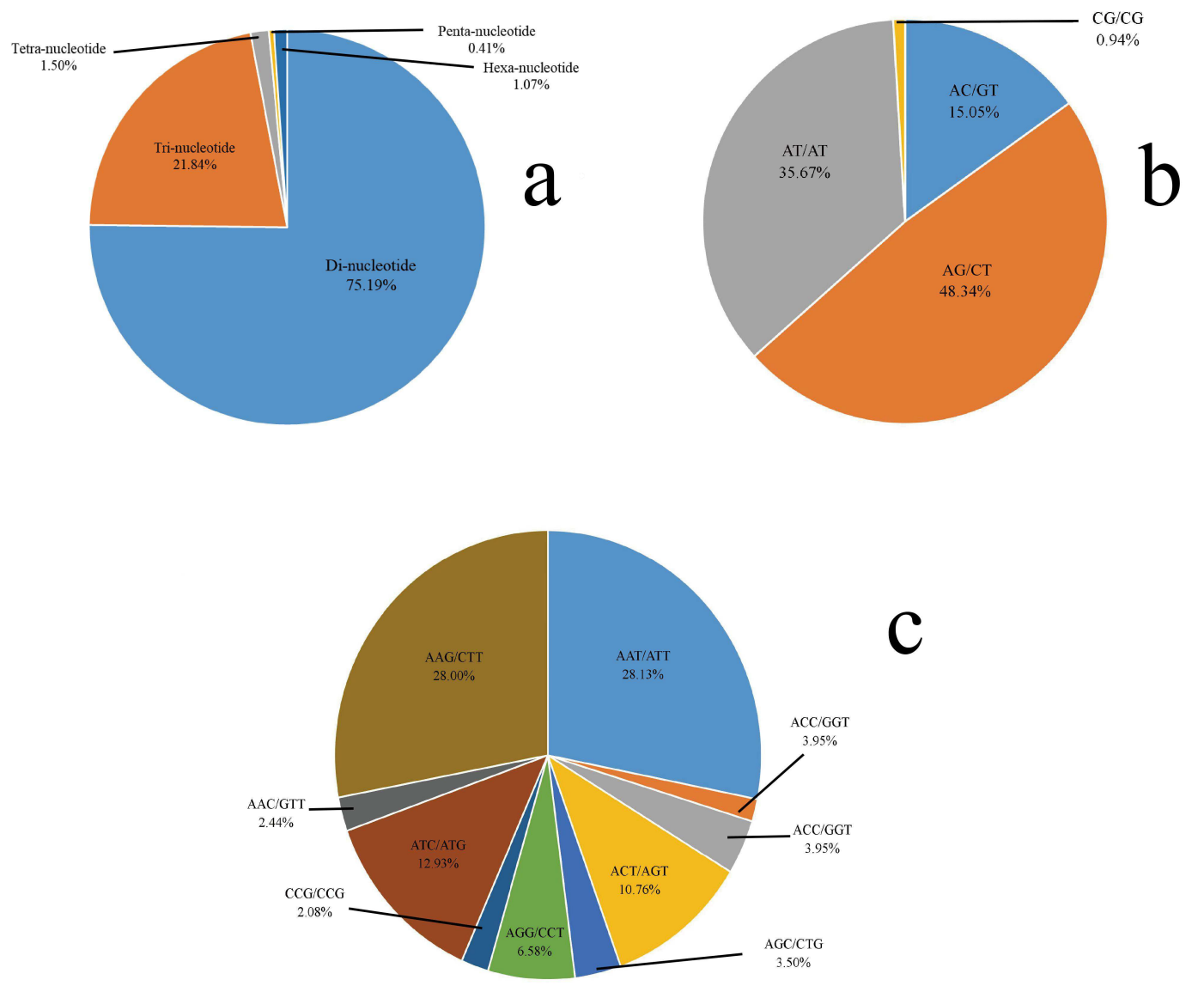

Fig. 4 Features of SSR markers. (a) The frequency of different SSR markers; (b) The

212 frequency of different dinucleotide SSR markers; (c) The frequency of different trinucleotide SSR

213 markers. 
motifs accounted for $48.34 \%$, AC/GT motifs accounted for $15.05 \%$, and $\mathrm{CG} / \mathrm{CG}$ motifs accounted

217 for only $0.94 \%$ (Fig. 4b). Among the predominant trinucleotide SSR markers, the AAT/ATT

218 repeat motif, AAG/CTT repeat motif and ATC/ATG repeat motif accounted for $28.13 \%, 28.00 \%$

219 and $12.93 \%$, respectively (Fig. 4c). 


\section{Discussion}

The genome of garlic, a member of the Liliaceae family, has been reported previously. The size of the sequenced garlic genome is $16.24 \mathrm{~Gb}$, accounting for $96.1 \%$ of the total garlic genome ${ }^{\text {[29] }}$. Among the representative monocots, the genome size of indica rice is $430 \mathrm{Mb}$, and the functional coverage is $92 \%{ }^{[30]}$; the genome size of japonica rice is $420 \mathrm{Mb}$, and the assembly coverage is $93 \%{ }^{[31]}$. The genome size of maize is $2.3 \mathrm{~Gb}^{[32]}$. According to our genome survey data, using all clean data for Genome Scoper analysis, the estimated size of the $N$. forrestii genome was $2.17 \mathrm{~Gb}$. Compared with the garlic genome, the whole genome of $N$. forrestii is small, but it is relatively large in monocots. With the development of NGS technology, whole-genome sequencing research has begun to be widely employed in horticultural plants, which may play an important role in understanding the key genes of $N$. forrestii.

GC content directly affects sequence bias ${ }^{[33]}$. GC content outside the $25-65 \%$ interval may cause sequence bias in Illumina sequencing. This problem is a notable one that affects the assembly of the genome ${ }^{[34]}$. The GC content of $N$. forrestii is $43.0 \%$, which is higher than that of potato $(34.8-36.0 \%)^{[35]}$, Luffa cylindrica $(37.9 \%)^{[36]}$, and humans $(41 \%)$ but lower than that of Gracilariopsis lemaneiformis $(48 \%)^{[37]}$.

From the 1,155,548,885-bp genome survey sequence, 34,552 SSRs without single nucleotide repeats were identified. Therefore, it is estimated that the distribution of SSRs in the genome of $N$. forrestii is approximately $29.90 \mathrm{SSR} / \mathrm{Mb}$, which is considerably lower than the $135.50 \mathrm{SSR} / \mathrm{Mb}$ measured in Arabidopsis ${ }^{[38]}$ and the $117.57 \mathrm{SSR} / \mathrm{Mb}$ detected in Luffa cylindrica. Among the dinucleotide repeat motifs, $\mathrm{AG} / \mathrm{CT}$ accounted for $48.34 \%$, which is the most abundant type, followed by AT/AT, accounting for 35.67\%; in the trinucleotide repeat sequence, AAT/ATT and 

respectively; among other polynucleotide repeats, AAAT/ATTT, AAAAT/ATTTT and

261 AAAAAG/CTTTTTT account for the highest proportions, and they are all A/T-rich motifs present in $N$. forrestii. This phenomenon is in keeping with the findings obtained by studies of other species, such as L. cylindrica ${ }^{[36]}$, ice $^{[39]}$, and Arabidopsis ${ }^{[40]}$. and analysis of the whole chloroplast genome may also provide evidence to determine the evolutionary level and phylogeny of $N$. forrestii. The results of this study also indicate that Nomocharis evolved from the genus Lilium.

\section{Conclusions}

N. forrestii has a $2.17 \mathrm{~Gb}$ heterozygous genome, its SSR markers are predominantly dinucleotides, and its chloroplast genome shows that $N$. forrestii and Lilium bakerianum have the highest homology followed by Lilium distichum.

Materials and Methods

\section{Materials} were provided by the School of Agricultural, Yunnan University.

\section{Methods}

Total genomic DNA extraction

280 Total genomic DNA was extracted from fresh leaves using the CTAB method ${ }^{[16]}$. 

sequencing. Sequencing was performed by Shaanxi Baiai Gene Information Technology Co., Ltd. sequencing data. SOAPdenovo (https://github.com/aquaskyline/SOAPdenovo2) software ${ }^{[41]}$ based on a De Bruijn Graph (version 1.05, BGI, Beijing, China) was employed to assemble clean data of high-quality reads. After assembly, the GC content information in the assembled genome was quantified.

\section{Genome Size Estimation and Genome Survey}

291 Clean data from high-quality reads were used for K-mer analysis. Based on the frequency distribution of K-mers $(\mathrm{k}=17)$, we used GenomeScope (https:/github.com/schatzlab/genomescope) to estimate the characteristics of the genome (genome size, duplicate content, and heterozygosity rate) ${ }^{[42]}$. Each read used $17 \mathrm{bp}$ as the window and $1 \mathrm{bp}$ as the step size to slide, and the total number of K-mers and the corresponding frequency were counted and calculated. Next, based on the K-mer depth distribution curve, the peak value (Peak_depth) was identified. Finally, according to the formula Genome Size = K-mer_num/Peak_depth, the genome size was calculated ${ }^{[16]}$.

The chloroplast genome was directly assembled with the help of NOVOPlasty 
of $L$. bakerianum. The chloroplast group genes of the samples were annotated with CPGAVAS (http://47.96.249.172:16014/analyzer/home) ${ }^{[24]}$ software. The annotation results were plotted using OGDRAW (https://chlorobox.mpimp-golm.mpg.de/OGDraw.html $)^{[44]} . \quad$ MEGAX (https://www.megasoftware.net) was used to analyze the whole genome sequence of $N$. forrestii and 24 other chloroplasts using the neighbor joining method to analyze the evolutionary tree.

\section{Identification and verification of SSRs}

Using MISA software (https://webblast.ipk-gatersleben.de/misa), 2,847,542 scaffolds were utilized for genome SSR marker detection. We set the following search parameters for identification: di-, tri-, tetra-, penta- and hexanucleotide motifs have at least 6, 5, 4, 4, and 4 repeats, respectively, as described by previous authors ${ }^{[16,29,37,45,46]}$.

\section{Abbreviations:}

SSR: Simple Sequence Repeats; NGS: next-generation sequencing; LSC: large single-copy region; SSC: small single-copy region; PCGs: protein-coding genes; tRNA: transfer RNA; rRNA: ribosomal RNA; MEGA: molecular evolutionary genetics analysis;

\section{Declarations}

\section{Ethics approval and consent to participate}

The plant materials used in this study were collected in Shangri-La, Yunnan and cultivated in the School of Agricultural, Yunnan University. They comply with national and international standards and local laws, and comply with the convention on trade in endangered species of wild 
Consent for publication

All authors have read and approved the manuscript.

The authors declare that they have no competing interests.

\section{Funding} data were recorded, tabulated and analyzed by two first authors who also assisted in preparing the draft of the manuscript.

\section{Authors' contributions}

343 Conceived and designed the experiments: X.W. Wu, L.H. Wang;

344 Performed the experiments: D. Zhang, L.L. Li;

345 Analyzed the data: D. Zhang, L.L. Li; 


\section{Acknowledgements}

We thank for B.Q. Huang to help us review the manuscript. We are particularly software.

\section{References}

356 1. Liang SY. Studies on the genus Nomocharis (Liliaceae). Bulletin of the of the Botanical

2. Wan J, Zhou SD, Gao YD, He XJ. Karyotypes of Twenty-five Populations of Thirtee Species in Nomocharis and Lilium. Plant Diversity and Resources.2011; 33(5):477-94. 5(2):273-97.https://doi.org/10.2307/4117245.

4. Wu ZY, Li H, Yang CR. Cytogeography and phylogeny of Lilieae. Acta Botanica Yunnanica.1994; s6:101-12.

5. Sealy JR. A revision of the genus Nomocharis Franchet. Botanical journal of the Linnean Society.1983; 87(4):285-323.https://doi.org/10.1111/j.1095-8339.1983.tb00996.x.

6. Yu H, Huang RF, Dang CL. A study on the polymorphism of morphological character of

8. Nishikawa T, Okazaki K, Uchino T, Arakawa K, Nagamine T. A molecular phylogeny of Lilium in the internal transcribed spacer region of nuclear ribosomal DNA. Journal of 
9. Hayashi K, Kawano S. Molecular systematics of Lilium and allied genera (Liliaceae): phylogenetic relationships among Lilium and related genera based on the $r b c L$ and matK gene sequence data.

Plant

Species

Biology.2000; 15(1):73-93.http://dx.doi.org/10.1046/j.1442-1984.2000.00025.x.

10. Cui GF, Wu LF, Wu XW, Zhang YP, Wang JH. Relationships among species in Nomocharis and Lilium based on ITS sequences [J]. Acta Botanica Boreali-Occidentalia Sinica.2008; 10.

11. Jiao Y, Jia HM, Li XW, Chai ML, Jia HJ, Chen Z, et al. Development of simple sequence repeat (SSR) markers from a genome survey of Chinese bayberry (Myrica rubra). BMC genomics.2012; 13(1):201.

12. Zhou W, Hu YY, Sui ZH, Fu F, Wang JG, Chang LP, et al. Genome survey sequencing and genetic background characterization of Gracilariopsis lemaneiformis (Rhodophyta) based on next-generation sequencing. PLoS One.2013; 8(7):e69909.

13. Wei X, Wang L, Zhang Y, Qi X, Wang X, Ding X, et al. Development of simple sequence repeat (SSR) markers of sesame (Sesamum indicum) from a genome survey. Molecules.2014; 19(4):5150-62.

14. He Y, Xiao HT, Deng C, Xiong L, Nie H, Peng C. Survey of the genome of Pogostemon cablin provides insights into its evolutionary history and sesquiterpenoid biosynthesis. Scientific Reports.2016; 6:26405.http://doi.org/10.1038/srep26405.

15. Xu DP, Li Y, Meng X, Zhou T, Zhou Y, Zheng J, et al. Natural antioxidants in foods and medicinal plants: Extraction, assessment and resources. International journal of molecular sciences.2017; 18(1):96.http://doi.org/10.3390/ijms 18010096.

16. Wang CR, Yan HD, Li J, Zhou SF, Liu T, Zhang XQ, et al. Genome survey sequencing of purple elephant grass (Pennisetum purpureum Schum 'Zise') and identification of its SSR markers.

\section{8(7):94.http://doi.org/10.1007/s11032-018-0849-3.}

17. Lu M, An HM, Li LL. Genome survey sequencing for the characterization of the genetic background of Rosa roxburghii tratt and leaf ascorbate metabolism Genes. PLoS One.2016; 11(2):e0147530.http://doi.org/10.1371/journal.pone.0147530. 
18. Motalebipour EZ, Kafkas S, Khodaeiaminjan M, Çoban N, Gözel H. Genome survey of pistachio (Pistacia vera L.) by next generation sequencing: development of novel SSR markers and genetic diversity in Pistacia species. BMC genomics.2016; 17(1):998.http://doi.org/10.1186/s12864-016-3359-x.

19. Atherton RA, McComish BJ, Shepherd LD, Berry LA, Albert NW, Lockhart PJ. Whole genome sequencing of enriched chloroplast DNA using the Illumina GAII platform. Plant methods.2010; 6(1):1-6.https://doi.org/doi:10.1186/1746-4811-6-22.

20. Lin CS, Chen JJ, Huang YT, Chan MT, Daniell H, Chang WJ, et al. The location and translocation of $n d h$ genes of chloroplast origin in the Orchidaceae family. Scientific reports.2015; 5:9040.http://doi.org/10.1038/srep09040.

21. Kocyan A, Zhang LB, Schaefer H, Renner SS. A multi-locus chloroplast phylogeny for the Cucurbitaceae and its implications for character evolution and classification. Molecular phylogenetics

and evolution.2007; 44(2):553-77.https://doi.org/10.1016/j.ympev.2006.12.022.

22. Li XW, Yang Y, Henry RJ, Rossetto M, Wang YT, Chen SL. Plant DNA barcoding: from gene to genome. Biological Reviews.2015; 90(1):157-66.http://doi.org/10.1111/brv.12104.

23. Daniell H, Lin CS, Yu M, Chang WJ. Chloroplast genomes: diversity, evolution, and applications in genetic engineering. Genome biology.2016; 17(1):134.http://doi.org/10.1186/s13059-016-1004-2.

24. Zuo LH, Shang AQ, Zhang S, Yu XY, Ren YC, Yang MS, et al. The first complete chloroplast genome sequences of Ulmus species by de novo sequencing: Genome comparative and $\begin{array}{llll}\text { taxonomic } & \text { position } & \text { Pnalysis. } & \text { One.2017; }\end{array}$ 12(2):e0171264.http://doi.org/10.1371/journal.pone.0171264.

25. Kumar S, Stecher G, Li M, Knyaz C, Tamura K. MEGA X: molecular evolutionary genetics analysis across computing platforms. Molecular biology and evolution.2018; 35(6):1547-9.http://doi.org/10.1093/molbev/msy096.

26. Saitou N, Nei M. The neighbor-joining method: a new method for reconstructing phylogenetic $\begin{array}{lll}\text { trees. } & \text { Molecular biology and }\end{array}$ 4(4):406-25.https://doi.org/10.1093/oxfordjournals.molbev.a040454. 
27. Felsenstein J. Confidence limits on phylogenies: an approach using the bootstrap. evolution.1985; 39(4):783-91.

28. Tamura K, Nei M, Kumar S. Prospects for inferring very large phylogenies by using the

29. Sun XD, Zhu SY, Li NY, Cheng Y, Zhao J, Qiao XG, et al. A chromosome-level genome

Plant.2020; 13(9):1328-39.http://doi.org/10.1016/j.molp.2020.07.019.

30. Yu J, Hu SN, Wang J, Wong GKS, Li SG, Liu B, et al. A draft sequence of the rice genome science.2002; 296(5565):79-92.https://doi.org/10.1126/science.1068037.

Science.2002; 296(5565):92-100.https://doi.org/10.1126/science.1068275. minimizing PCR amplification bias in Illumina sequencing libraries. Genome biology.2011;

35. Hirakawa H, Okada Y, Tabuchi H, Shirasawa K, Watanabe A, Tsuruoka H, et al. Survey of genome sequences in a wild sweet potato, Ipomoea trifida (HBK)

G. Don. DNA Research.2015; 22(2):171-9.http://doi.org/10.1093/dnares/dsv002. 
37. An JY, Yin MQ, Zhang Q, Gong DY, Jia XW, Guan YJ, et al. Genome survey sequencing of Luffa Cylindrica L. and microsatellite high resolution melting (SSR-HRM) analysis for genetic relationship of Luffa genotypes. International Journal of Molecular Sciences.2017; 18(9):1942.https://doi.org/10.3390/ijms18091942.

38. Zhao HS, Yang L, Peng ZH, Sun HY, Yue XH, Lou YF, et al. Developing genome-wide microsatellite markers of bamboo and their applications on molecular marker assisted taxonomy for accessions in the genus Phyllostachys. Scientific reports.2015; 5(1):1-10.http://doi.org/10.1038/srep08018.

39. Temnykh S, DeClerck G, Lukashova A, Lipovich L, Cartinhour S, McCouch S. Computational and experimental analysis of microsatellites in rice (Oryza sativa L.): frequency, length variation, transposon associations, and genetic marker potential. Genome research.2001; 11(8):1441-52.https://dx.doi.org/10.1101\%2Fgr.184001.

40. Katti MV, Ranjekar PK, Gupta VS. Differential distribution of simple sequence repeats in eukaryotic genome sequences. Molecular biology and evolution.2001; 18(7):1161-7.https://doi.org/10.1093/oxfordjournals.molbev.a003903.

41. Wang RK, Fan JS, Chang P, Zhu L, Zhao MR, Li LL. Genome survey sequencing of Acer truncatum bunge to identify genomic information, simple sequence repeat (SSR) markers and complete chloroplast genome. Forests.2019; 10(2):87.http://doi.org/10.3390/f10020087.

42. Vurture GW, Sedlazeck FJ, Nattestad M, Underwood CJ, Fang H, Gurtowski J, et al. GenomeScope: fast reference-free genome profiling from short reads. Bioinformatics.2017; 33(14):2202-4.http://doi.org/10.1093/bioinformatics/btx153.

43. Hahn C, Bachmann L, Chevreux B. Reconstructing mitochondrial genomes directly from genomic next-generation sequencing reads - a baiting and iterative mapping approach. Nucleic acids research.2013; 41(13):e129-e.

44. Lohse M, Drechsel O, Kahlau S, Bock R. OrganellarGenomeDRAW-a suite of tools for generating physical maps of plastid and mitochondrial genomes and visualizing expression data sets. Nucleic acids research.2013; 41(W1):W575-W81.

45. Wang RK, Liu P, Fan JS, Li LL. Comparative transcriptome analysis two genotypes of Acer truncatum Bunge seeds reveals candidate genes that influences seed VLCFAs accumulation. 
489 46. Li LL, Zhang HH, Liu ZS, Cui XY, Zhang T, Li YF, et al. Comparative transcriptome

490 sequencing and de novo analysis of Vaccinium corymbosum during fruit and color

$\mathrm{BMC}$

plant

biology.2016; 
Figures

len:2,171,937,001 bp uniq:15.3\% het:3.99\% kcov:14.9 err:0.752\% dup:0.985\% $k: 17$

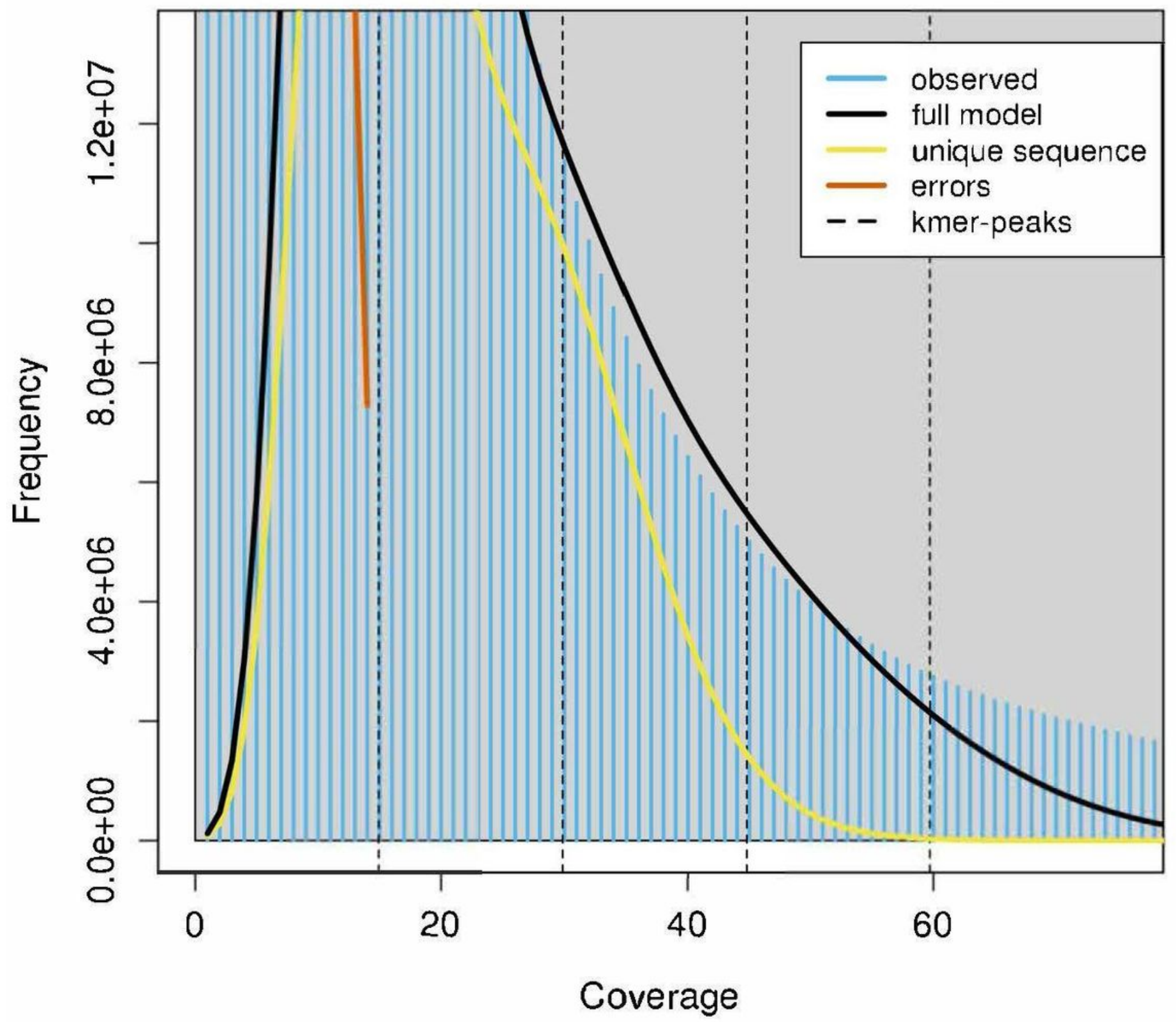

Figure 1

K-mer distribution calculated by GenomeScope. The blue bar represents the observed K-mer distribution;the black linerepresents no K-mer,the redline represents the errormodel distribution;and theyellowlinerepresentsthemaximum K-mercoveragespecifiedinthemodel 


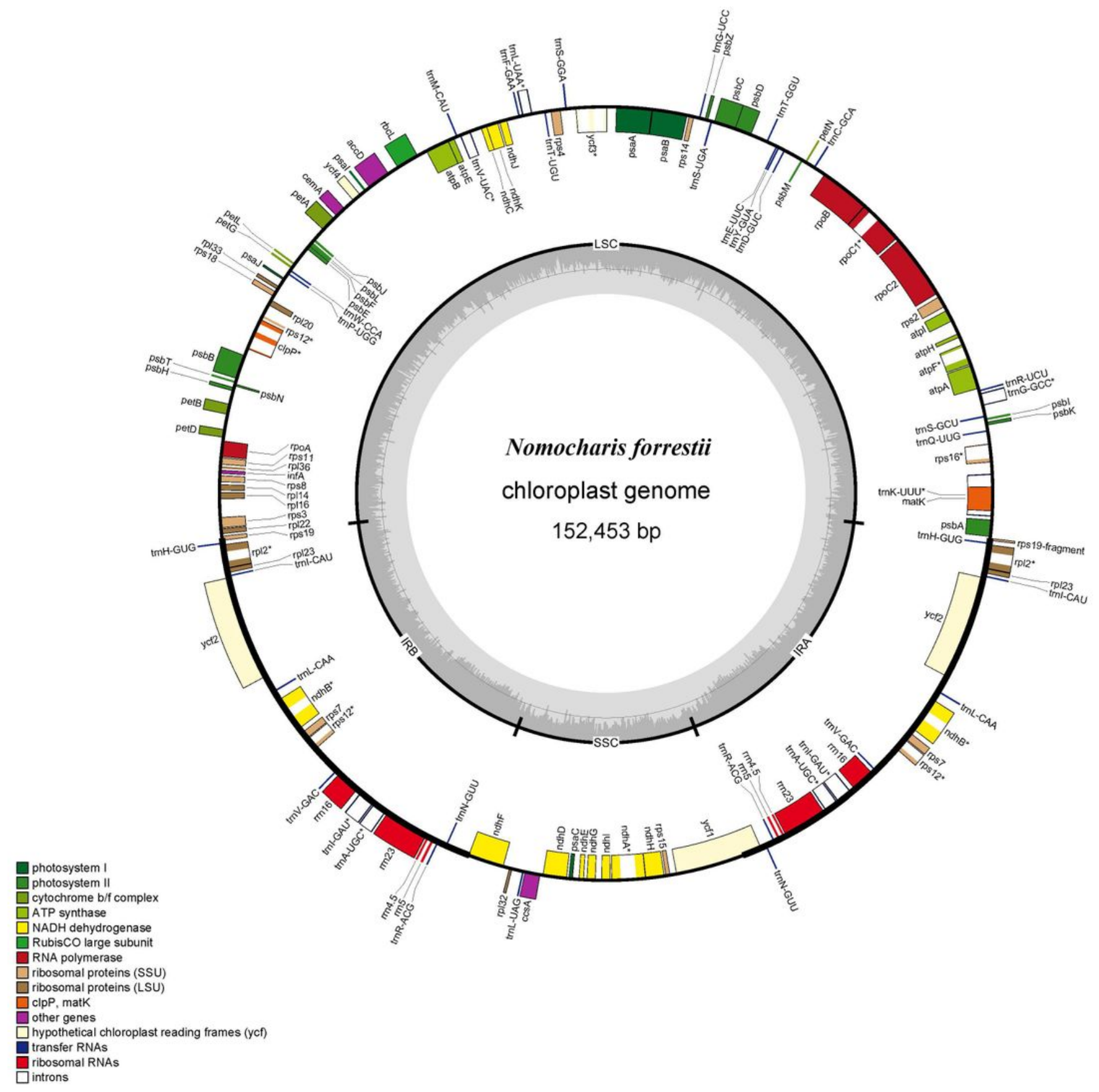

Figure 2

Chloroplast genome of Nomocharis forrestii 


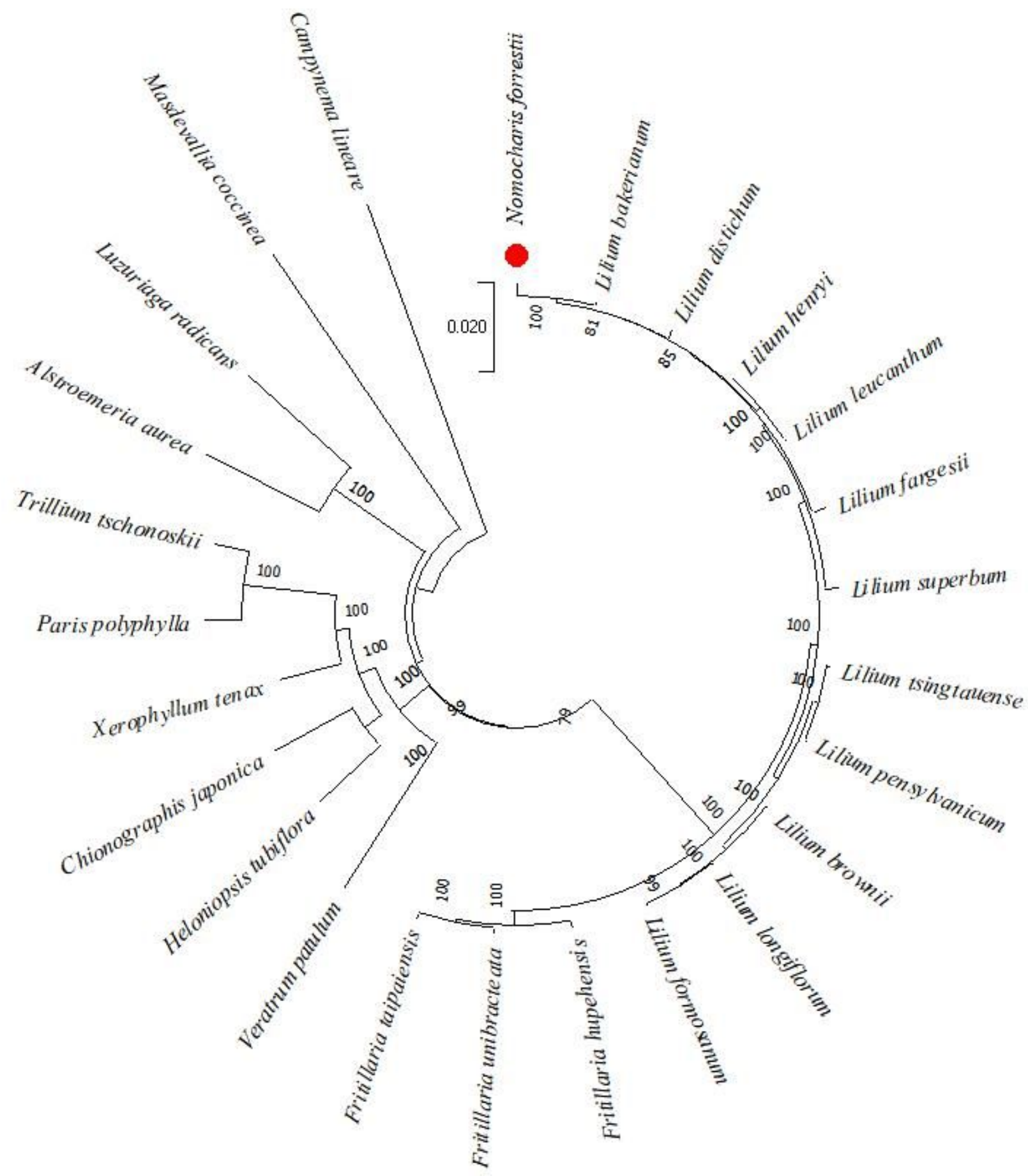

Figure 3

Molecular phylogeny of 15 Liliaceae plants based on whole chloroplast sequence 

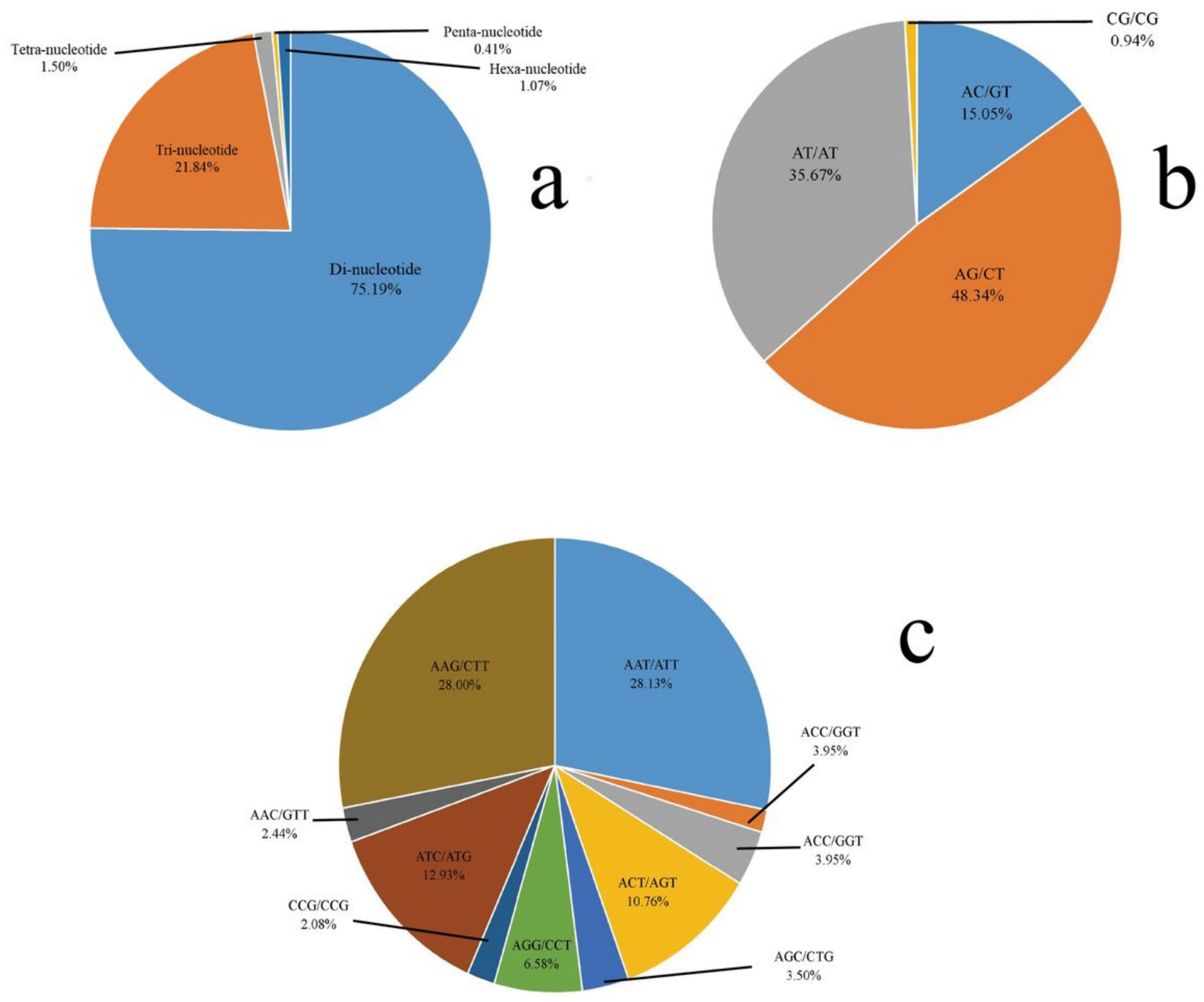

Figure 4

FeaturesofSSRmarkers.(a)Thefrequency of differentSSRmarkers;(b)The frequencyofdifferentdinucleotideSSRmarkers;(c)Thefrequency ofdifferenttrinucleotideSSR markers 


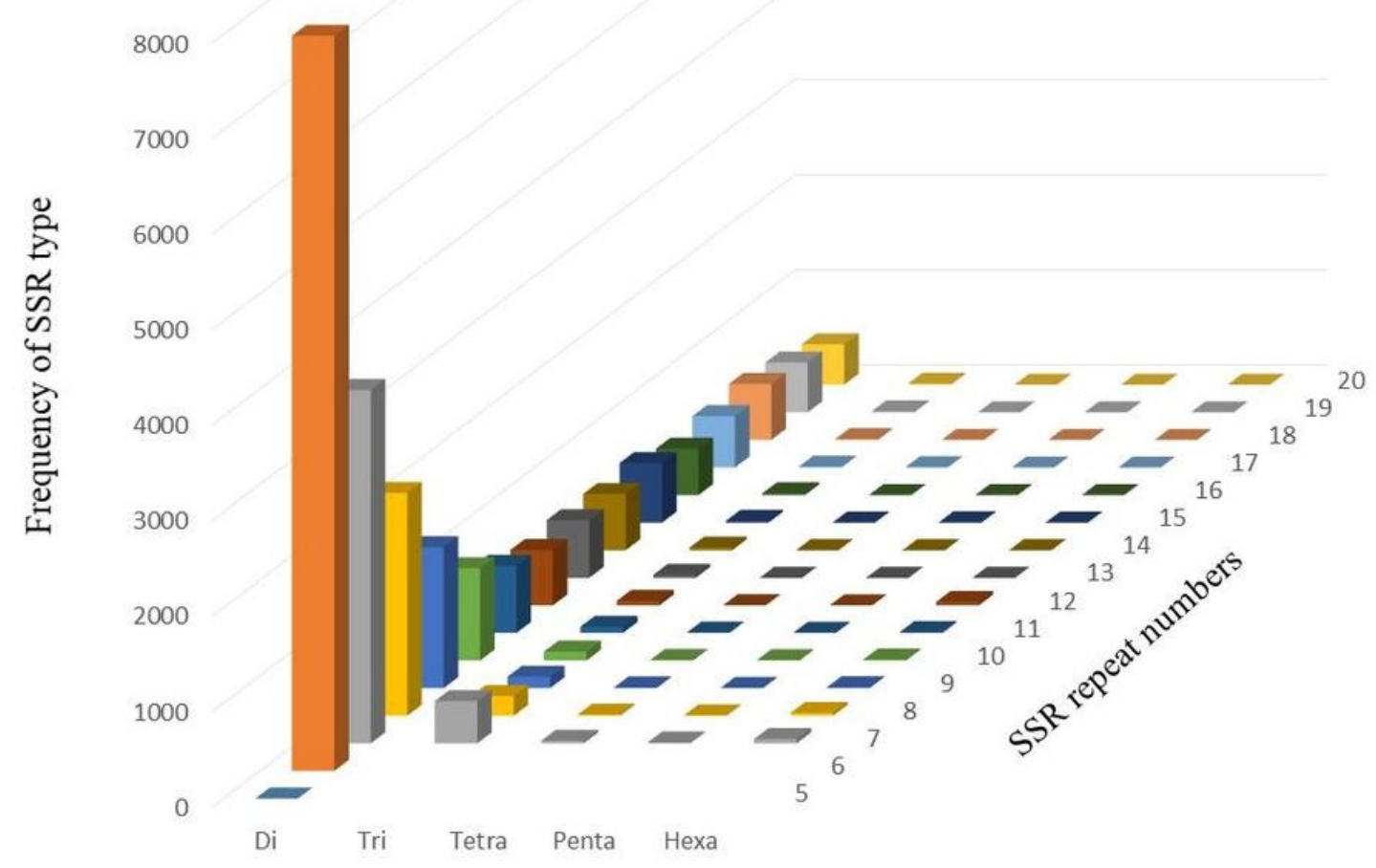

Figure 5

Distribution and frequency of SSR motif repeats 